\title{
Anxiolysis and recognition memory enhancement with long-term supplemental ascorbic acid (vitamin C) in normal rats: possible dose dependency and sex differences
}

\author{
Robert N. Hughes", Nicola J. Hancock and Rikki M. Thompson
}

*Correspondence: rob.hughes@canterbury.ac.nz

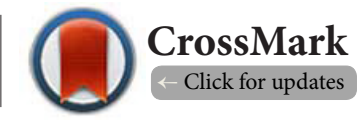

Department of Psychology, University of Canterbury, Private Bag 4800, Christchurch 8140, New Zealand.

\begin{abstract}
To investigate a possible dose-response relationship and sex differences for anxiolytic and memoryenhancing effects of ascorbic acid (vitamin C), an adult PVG /c hooded rats were individually treated for 8 weeks with approximately 61,114 or $160 \mathrm{mg} / \mathrm{kg} /$ day of ascorbic acid in their drinking water. After their treatment, over 3 consecutive days they experienced a 5 -min trial in an open field (OF) followed by a 5 -min trial in an elevated plus maze (EPM), and then finally a 5 -min novel object recognition (NOR) test in the OF. Dose-related anxiolytic effects were observed that to some extent depended on the measure of anxiety. In other words, anxiolytic effects were evident in higher frequencies of walking with $114 \mathrm{mg} / \mathrm{kg}$ and $61 \mathrm{mg} / \mathrm{kg}$, higher frequencies of rearing and lower frequencies of grooming in the $\mathrm{OF}$ as well as more frequent occupation of the EPM open arms. Rats treated with $160 \mathrm{mg} / \mathrm{kg}$ explored a novel versus familiar object in the NOR test to a significantly greater extent than control rats thereby suggesting enhancement of their recognition memory. Overall, it appeared that the anxiolytic effects of ascorbic acid were more typical of the lowest dose, whereas memory enhancement appeared to be confined to the highest dose. While there were a number of significant sex differences, there was no evidence of differences between females and males in the effects of ascorbic acid.
\end{abstract}

Keywords: Ascorbic acid, anxiolysis, rats, open field, elevated plus maze, novel object recognition

\section{Introduction}

Ascorbic acid (vitamin C) is a powerful antioxidant with a number of effects on the brain including protection against oxidative damage [1], involvement in catecholamine synthesis, and possible neuromodulation of neural transmission viaglutamine, dopamine, acetylcholine and GABA along with associated behavioral responses [2]. During the last 20 years, there has been increasing interest in the possible anxiolytic effects of ascorbic acid supplementation even when there is no evidence of a deficiency in its endogenous form, namely ascorbate. For example, it has been shown that 14 days of treatment of normal human volunteers with $3 \mathrm{~g}$ of ascorbic acid reduced salivary cortisol, blood pressure and subjective anxiety in response to a psychological stressor [3]. Ascorbic acid's anxiolytic potential has also been suggested by reports of it decreasing neophobia and measures of fear in poultry $[4,5]$, reducing avoidance of an aversive environ- ment in mice [6], alleviating behavioral and biochemical stress responses to electroshock in mice [7], attenuating anxiogenic effects of prolonged exposure to loud noise in mice [8], and decreasing several forms of anxiety-related behavior in rats [9]. As the rats in our earlier study [9] were provided with only one level of chronic ascorbic acid in their drinking water (approximately $80 \mathrm{mg} / \mathrm{kg} /$ day), one of the aims of the present study was to determine if doses lower and higher than this would have comparable anxiolytic effects.Some evidence of dose-related effectiveness of the vitamin has been reported by Choi et al [7]. Therefore, effects of treatment with three doses of ascorbic acid on anxiety-related behavior were recorded in an open field and an elevated plus maze. Both types of apparatus are commonly used for assessing anxiety levels in rats $[10,11]$.

Improved impaired memory following intraperitoneal or intravenous ascorbic acid administration has been illustrated 
by several examples of reduced age-related and drug-induced memory deficits in rats $[\mathbf{1 1}]$ and mice $[\mathbf{6}, \mathbf{1 3}, \mathbf{1 4}]$. Such findings support the suggestion that ascorbic acid can protect against the cognitive decline accompanying neurodegenerative disorders, such as Alzheimer's Disease $[\mathbf{2 , 1 5}]$, which are characterized by ascorbate deficiencies $[16,17]$. However, there has been significantly less research into effects of ascorbic acid supplementation on unimpaired memory in healthy subjects. Of the few studies on record, one has shown that long-term oral administration (30 days) of both 60 and $120 \mathrm{mg} / \mathrm{kg}$ of the vitamin significantly enhanced passive avoidance learning and memory in rats [18]. More recently it was reported that acute intravenous ascorbic acid improved spatial memory in mice [19]. Therefore, a second aim of the present study was to assess the effects of ascorbic acid on recognition memory in normal rats as reflected in a novel object recognition task. This task involves evaluating preferences for a novel versus familiar object and has become a popular way of measuring recognition memory in rodents [20]. As previously [9], ascorbic acid was added to rats' drinking water in quantities designed to achieve three daily doses. These were 60 and $120 \mathrm{mg} / \mathrm{kg}$ (as administered by Shahidi et al., [18]) plus an additional higher dose of $180 \mathrm{mg} / \mathrm{kg}$.

\section{Methods}

The subjects were 40 female and 40 male hooded rats of the PVG/c strain bred on the Animal Facility of the Department of Psychology, University of Canterbury, Christchurch, New Zealand. They were weaned at 30 days of age and kept in groups of 4 same-sexed animals until the beginning of ascorbic acid exposure approximately 140 days later. The rats were then randomly assigned to a control or one of 3 ascorbic acid groups in same-sexed pairs in 560x350x215-mm (lengthxwidthxheight) plastic cages. The two members of each pair were separated from each other by a $560 \times 215-\mathrm{mm}$ (lengthxheight) wire partitions that enabled visual, auditory and olfactory but not physical contact. This enabled individual measurements of volumes of water or ascorbic acid drunk (see below) without the rats being totally socially isolated. All cages were kept in $12 \mathrm{~h}$ light: $12 \mathrm{~h}$ dark illumination (lights on at $700 \mathrm{~h}$ ) with an ambient temperature of $20 \pm 1^{\circ} \mathrm{C}$. There were 10 females and 10 males in each of the 4 groups. All animals had ad libitum access to standard laboratory rat food pellets.

All treatment and testing procedures complied with the requirements of Parts 5 (Codes of Welfare) and 6 (Use of Animals in Research, Testing and Teaching) of the New Zealand Animal Welfare Act, 1999, and had been approved by the University of Canterbury's Animal Ethics Committee (approval number 2013/14R).

\section{Preparation of and treatment with ascorbic acid solutions}

Ascorbic acid powder was dissolved in tap water in amounts designed to achieve target doses of approximately 60, 120 and $180 \mathrm{mg} / \mathrm{kg} / \mathrm{day}$ on the basis of earlier established volumes of water drunk each day by individual PVG/c rats [9]. After taking into account differences between the two species in body surface area [21], these doses for rats were equivalent to $0.73,1.45$ and $2.28 \mathrm{~g} /$ day of ascorbic acid for an average $75.6 \mathrm{~kg}$ adult human (based on body weight data for Europe and North America [22]). Doses of this magnitude are well tolerated and without adverse effects $[\mathbf{2 3}, 24]$. Since females typically drink more than males, the quantities of ascorbic acid that were added to the rats drinking water were different for each sex to ensure that they both consumed equivalent daily doses. The resulting drinking fluids were provided ad libitum up to and including the 3-day testing period. Every second (and occasionally third) day for the duration of the study, each rat was weighed and, when its drinking bottle was topped up, its daily consumption of ascorbic acid $(\mathrm{mg} / \mathrm{kg})$ was calculated from the volume of fluid drunk since the last measurement. Once a week, all bottles were replaced with sterilized ones containing freshly prepared solutions.

\section{Testing apparatus}

Behavioral effects of treatment with ascorbic acid were measured in an open field (OF) and an elevated plus maze (EPM). The interior of the $900 \times 900 \times 300-\mathrm{mm}$ high wooden OF was painted black, and the floor was divided into 16 numbered squares by means of a grid of intersecting white lines. A small 200x150x195 $\mathrm{mm}$ (lxwxh) wooden start box, with a hinged lid, was attached to the outside of one wall that enabled access to the interior of the apparatus through a slide-controlled $100 \times 100-\mathrm{mm}$ opening. The OF sat on a $700 \mathrm{~mm}$-high table and was illuminated by overhead fluorescent room lighting.

The wooden EPM comprised four $500 \mathrm{~mm}$-longx $100-\mathrm{mm}$ wide arms extending (at $90^{\circ}$ to each other) from a central 150-mmx150-mm platform. Two of the arms facing each other had 245-mm-high side and end walls comprising clear Perspex (the open arms) while the same walls of the other two were constructed from black-painted wood (the closed arms). Although the presence of transparent walls on the open arms is not conventional practice, they prevent a startled rat from leaping off the arm and do not appear to reduce its aversiveness [25] and thus anxiogenic properties [26]. The maze was evenly illuminated by overhead fluorescent room lighting and sat on a $1 \mathrm{~m}$-high stand.

\section{General procedure}

After 8 weeks of ascorbic acid treatment, all rats received a trial in the OF, followed the next day by a trial in the EPM, and finally on the third day, a novel object recognition trial (NOR). The responses were recorded by means of a momentary timesampling procedure whereby, every $3 \mathrm{~s}$ (indicated by an auditory signal and ear piece), each rat's location in the apparatus was noted and, where relevant, what type of behavior it was engaged in. Such procedures have proved to be accurate and reliable for estimating frequencies and duration of events [27]. For example, time-sampling has been shown to produce test-retest reliability coefficients of between 0.93 and 0.98 , and validity coefficients of 0.87 and 0.99 [28]. All observations were made via CCTV with 
the camera above the apparatus and the monitor and observer situated some distance away. Following a trial, the apparatus was thoroughly washed and dried before the next rat's test.

\section{OF testing}

Each rat was placed in the start box and then allowed access to the interior of the OF by removal of the slide. The time taken for the rat to fully emerge was recorded, the slide was replaced and then, every $3 \mathrm{~s}$ for $5 \mathrm{~min}$, it was noted which square the rat was occupying and if it was engaged in one of the following responses: walking within or between squares (walking), standing up on its hind legs either unsupported or leaning against a wall (rearing), licking its body (grooming) or remaining totally motionless (immobile). At the same time, it was noted if the rat was occupying one of the four center squares (center occupancy) or corners (corner occupancy) of the apparatus. High frequencies of walking, rearing and center occupancy is regarded as indices of low anxiety, while high frequencies of grooming, immobility and corner occupancy are thought to reflect high anxiety $[11,29]$. From square occupancy data it was also possible to estimate distance travelled (ambulation) by counting the number of times the rat was in a different square from that occupied when the immediately preceding $3 \mathrm{~s}$ signal occurred $[26,30,31]$. At the completion of its trial, the rat was allowed to freely explore the OF for a further $5 \mathrm{~min}$ as additional familiarization with the apparatus in preparation for the NOR trial to be experienced on the third testing day (see below).

\section{EPM testing}

Each rat was placed on the central platform of the apparatus facing one of the closed arms and continuously observed for 5 min. Its entries (all four feet) into each arm were counted and every $3 \mathrm{~s}$ the arm being occupied by the rat was noted. It was subsequently possible to calculate the rat's percentage of entries into the open arms and the percentage of $3 \mathrm{~s}$ observations when occupying these arms. These two measures are indicative of willingness to visit the anxiety-inducing unenclosed parts of the apparatus [10]. The total number of entries into the closed arms comprised a measure of locomotor activity that is relatively uncontaminated by anxiety [32].

\section{NOR testing}

For all rats, the familiar objects were two weighted $300-\mathrm{ml}$ empty drink cans, $115 \mathrm{~mm}$ high and with a diameter of $60 \mathrm{~mm}$. The novel object was a stop clock $115 \mathrm{~mm}$ high, $115 \mathrm{~mm}$ wide and $45 \mathrm{~mm}$ deep. In an earlier independent experiment, any preference for one object rather than the other (irrespective of their novelty values) had been assessed in 20 adult PVG/c hooded rats that were not part of the present study. The as sessment involved placing the can and stop clock in diagonal quadrants of an open field and, via CCTV, recording every 3 $\mathrm{s}$ for $5 \mathrm{~min}$, if the rat was in physical contact with and sniffing or manipulating either object. The position of each object was alternated for different rats. It was accordingly shown that the mean \pm SEM numbers of contacts made with the can and clock were $5.15 \pm 1.17$ and $3.30 \pm 0.85$ respectively. The difference between these values was not significant $\left(\mathrm{F}_{(1,36)}=1.97, \mathrm{p}>0.1\right)$, although female rats made significantly more contacts with both than males (females $=6.20 \pm 1.12$, males $=2.25 \pm 0.73, \mathrm{~F}_{(1,36)}=8.99, \mathrm{p}<0.01$ ).

For a NOR trial,the two cans were placed in diagonal corners of the OF, $10 \mathrm{~cm}$ from the walls. Each rat was then placed in the center of the OF and allowed to explore the apparatus and cans for $5 \mathrm{~min}$ after which time it was removed and returned to a holding cage. One of the cans was replaced by the stop clock (the position of which differed for different rats) and then, 15 min later, the rat was put back into the center of the OF. Every $3 \mathrm{~s}$ for $5 \mathrm{~min}$ it was noted if it was sniffing or manipulating the novel or the familiar object. A NOR discrimination index was calculated as follows:

$$
\text { NOR discrimination index }=\frac{\begin{array}{l}
\text { novel object exploration }- \\
\text { familiar object exploration }
\end{array}}{\text { total exploration }}
$$

An index greater than zero indicates more exploration of the novel than the familiar object, whereas an index of less than zero indicates the opposite [33].

\section{Statistical analysis}

Unless stated otherwise, all data were subjected to separate 4 (treatment) $\mathrm{x} 2$ (sex) ANOVAs using the Statview ${ }^{\mathrm{TM}}$ SE II statistics package for Macintosh computers. Post hoc comparisons were made by means of Fisher PLSD tests $(\mathrm{p}<0.05)$.

\section{Results \\ Doses, fluid drunk and body weights}

Determination of the rats' average ascorbic acid consumption for each of the three treatment conditions revealed approximate daily doses of 61,114 and $160 \mathrm{mg} / \mathrm{kg}$ (to the nearest whole number). The mean \pm SEM volumes of average fluid drunk each day ( $\mathrm{ml} / 100 \mathrm{~g}$ body weight) for the control and three ascorbic acid groups (both sexes combined) were $9.34 \pm 1.05,8.21 \pm 0.59$, $7.71 \pm 0.67$ and $7.23 \pm 0.59$ respectively. The differences between the groups were not significant $\left(\mathrm{F}_{(3,72)}=1.46, \mathrm{p}>0.2\right)$. However, for all groups combined, female rats drank significantly more fluid each day than males (females $=10.95 \pm 0.40$, males $=5.30 \pm 0.11$, $\left.\mathrm{F}_{(1,72)}=232.58, \mathrm{p}<0.0001\right)$.

Respective mean \pm SEM body weights $(\mathrm{g})$ for the control and three treatment groups (both sexes combined) were $298.84 \pm 20.22$, $300.66 \pm 22.51,291.37 \pm 20.77$ and $290.20 \pm 19.54$. While there were no significant group differences between these weights $\left(F_{(3,72)}=0.06, p>0.9\right)$, male rats were significantly heavier than females $\left(\mathrm{F}_{(1,72)}=2180.91, \mathrm{p}<0.0001\right)$.

\section{Behavioral results}

For ease of inspection, the effects on all responses of treatment with the different doses of ascorbic acid for both sexes combined are presented in Figures 1, $\mathbf{2}$ and $\mathbf{3}$ whereas sex differences for all treatment conditions combined (along with results of ANOVAs) are displayed in Table 1. 


\section{OF responses}

Effects of treatment with ascorbic acid for both sexes combined on all OF responses except emergence latencies and immobility are outlined in Figure 1. Although emergence latencies were not significantly affected by ascorbic acid ([control] mean \pm SEM $=111.45 \pm 44.60 \mathrm{~s}, 61 \mathrm{mg} / \mathrm{kg} /$ day $=99.35 \pm 20.34 \mathrm{~s}$, $114 \mathrm{mg} / \mathrm{kg} / \mathrm{day}=79.60 \pm 12.21 \mathrm{~s}, 160 \mathrm{mg} / \mathrm{kg} /$ day $=82.45 \pm 19.25$ $\left.\mathrm{s}, \mathrm{F}_{(3,72)}=0.33, \mathrm{p}>0.8\right)$, female rats emerged significantly faster than males (see Table 1).

An ANOVA of immobility data was not appropriate as the response was observed too infrequently among ascorbic acid treated rats. However, while 14 (70\%) of the 20 control animals were seen to be immobile at least once during the test session, none of the rats in either the 61 or $114 \mathrm{mg} / \mathrm{kg} /$ day group, and only $2(10 \%)$ in the $160 \mathrm{mg} / \mathrm{kg} /$ day group were immobile at least once. As shown by a chi-square test, the difference between all ascorbic acid-treated rats combined and control animals was significant $\left(\mathrm{X}_{(1)}=41.66, \mathrm{p}<0.001\right)$. Of the 40 females, $7(18 \%)$ were immobile at least once compared with $9(23 \%)$ of the 40 males. Clearly this difference was not significant $\left(\mathrm{X}_{(1)}=0.31, \mathrm{p}>0.5\right)$.

Neither ambulation (Figure 1A, $\mathrm{F}_{(3,72)}=0.89, \mathrm{p}>0.4$ ) nor corner occupancy (Figure 1F, $\mathrm{F}_{(3,72)}=0.31, \mathrm{p}>0.8$ ) were significantly

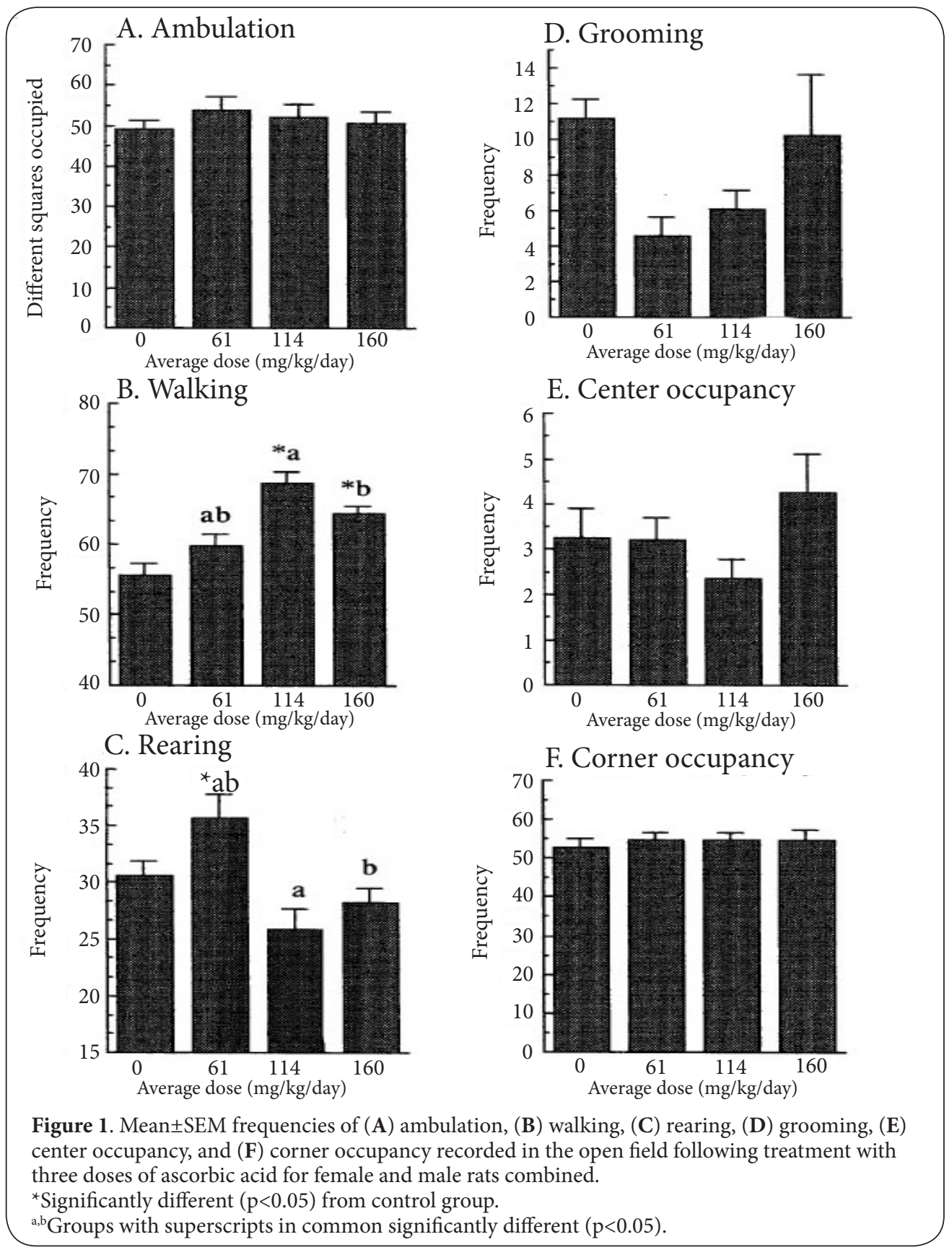




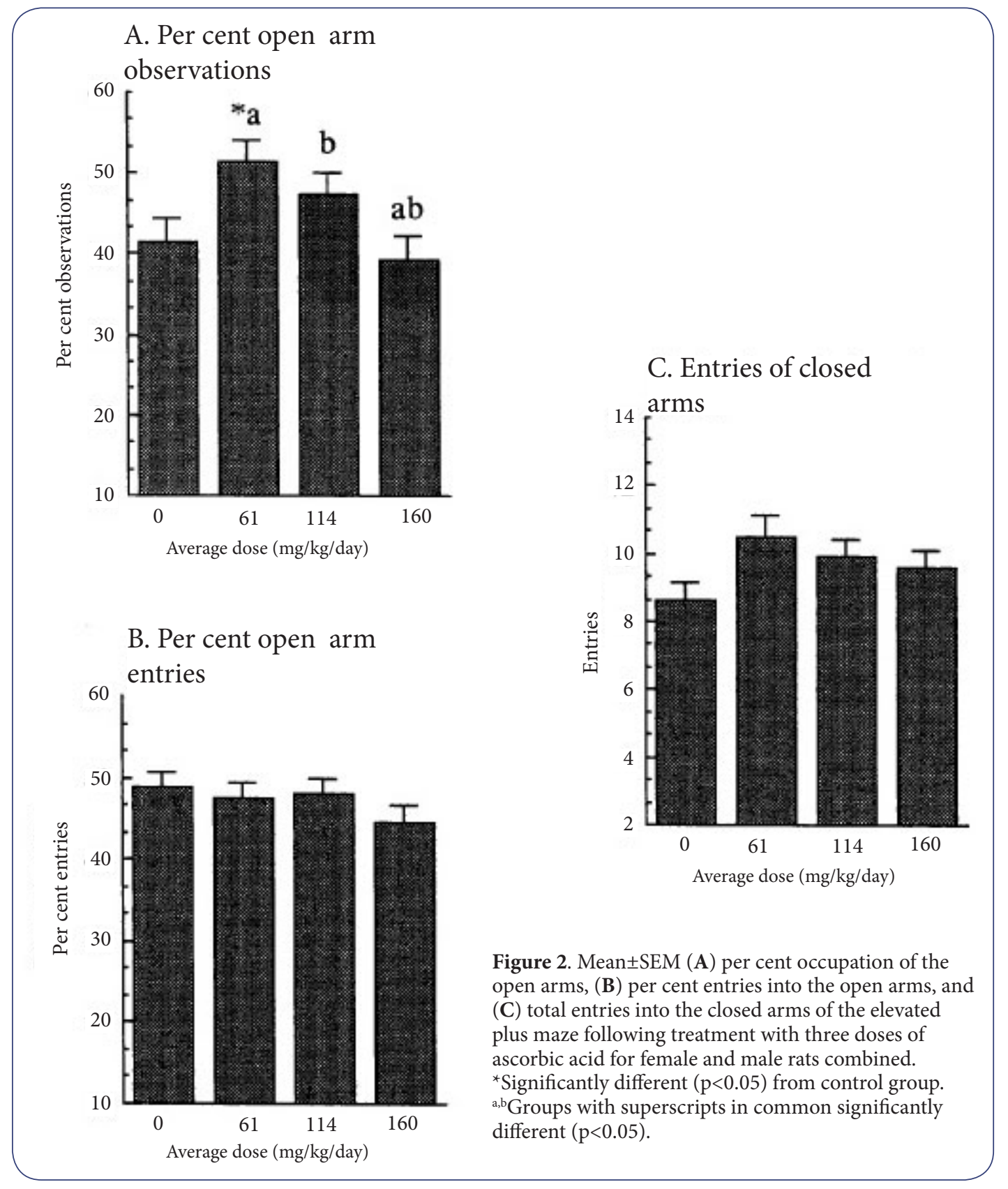

affected by ascorbic acid, but a significant effect occurred for walking (Figure 1B, $\mathrm{F}_{(3,72)}=12.89, \mathrm{p}<0.0001$ ). This was due to significantly higher frequencies of the response with the two highest doses (114 and $160 \mathrm{mg} / \mathrm{kg} /$ day) than was the case for either the control or lowest dose $(61 \mathrm{mg} / \mathrm{kg} /$ day $)$. Rearing was also significantly affected by ascorbic acid (Figure $1 \mathrm{C}, \mathrm{F}_{(3,72)}=6.80$, $\mathrm{p}<0.0005)$ due to significantly higher frequencies in the lowest dose group $(61 \mathrm{mg} / \mathrm{kg} / \mathrm{day})$ than in any other group. Although rats treated with the lowest dose groomed less often than those in any other group, the treatment effect failed to reach significance (Figure 1D, $\mathrm{F}_{(3,72)}=2.58, \mathrm{p}=0.056$ ).
As shown in Table 1, female rats exhibited significantly higher frequencies of ambulation and center occupancy, and a suggestive (but not significant) higher frequency of rearing than males. They also occupied the corners of the apparatus significantly less often than males.

\section{EPM responses}

Effects of treatment with the three doses of ascorbic acid on responses recorded in the EPM are shown in Figure 2.

While the effect was significant for per cent observations in the open arms (Figure 2A, $\mathrm{F}_{(3,72)}=4.34, \mathrm{p}<0.008$ ), this was not 


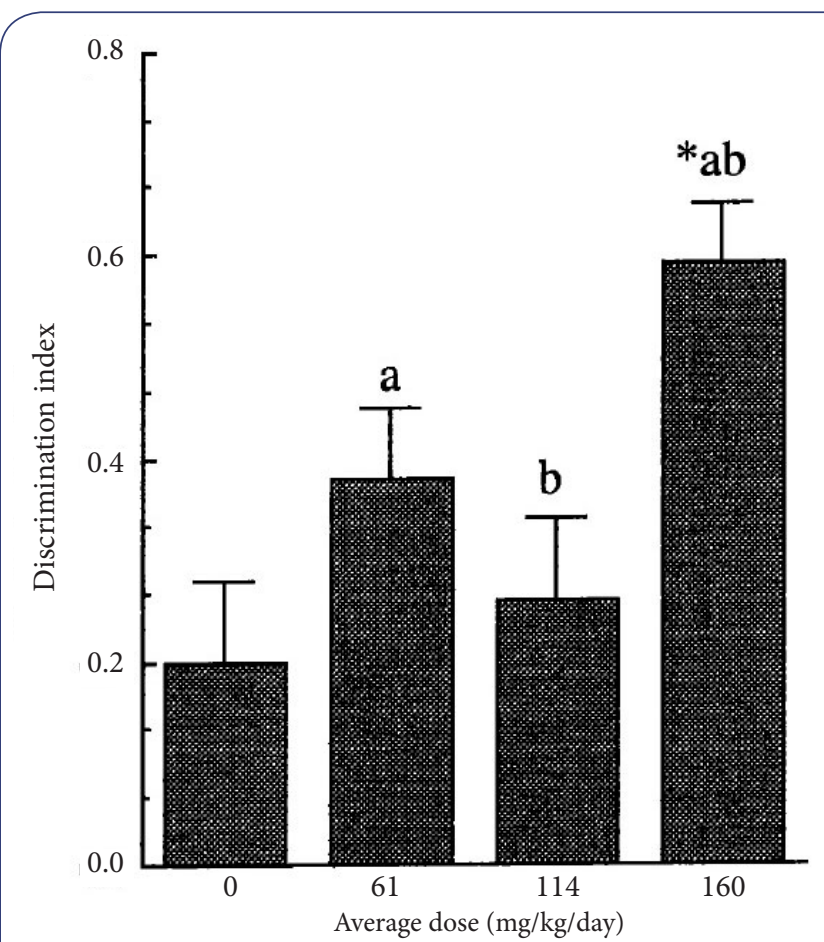

Figure 3. Mean \pm SEM discrimination indices for female and male rats combined following treatment with three doses of ascorbic acid obtained from exploration of novel and familiar objects in the novel object recognition task.

* Significantly different $(\mathrm{p}<0.05)$ from control group.

${ }^{\mathrm{a}, \mathrm{b}}$ Groups with superscripts in common significantly different $(\mathrm{p}<0.05)$. so for either per cent entries into the open arms (Figure 2B, $\left.F_{(3,72)}=0.90, p>0.4\right)$ or total entries into the closed arms (Figure 2C, $\left.\mathrm{F}_{(3,72)}=1.42, \mathrm{p}>0.2\right)$. The significant effect for observations in the open arms was due to rats treated with $61 \mathrm{mg} / \mathrm{kg} /$ day occupying these arms significantly more often than rats in any other group. Female rats were seen significantly more often in the open arms and entered the closed arms more often than males (see Table 1).

\section{NOR}

The mean \pm SEM total number of contacts with both objects for each treatment group were: control $=19.95 \pm 3.75,61 \mathrm{mg} / \mathrm{kg} /$ day $=19.60 \pm 1.99,114 \mathrm{mg} / \mathrm{kg} /$ day $=19.35 \pm 2.29$, and $160 \mathrm{mg} / \mathrm{kg} /$ day $=15.40 \pm 1.89, \mathrm{~F}_{(3,72)}=0.68, \mathrm{p}>0.5$. Clearly ascorbic acid treatment did not affect this measure. Effects of ascorbic acid on the NOR discrimination index can be seen in Figure 3.

The index was greater than zero for each group which meant that they all explored the novel more than the familiar object [33]. Mean \pm SEM percentages of exploration of the novel versus familiar object for the control and each ascorbic acid group $(61,114$ and $160 \mathrm{mg} / \mathrm{kg} /$ day) respectively, were $60.15 \pm 3.85$, $68.82 \pm 3.45,63.11 \pm 3.98$ and $79.47 \pm 3.07$. As shown by one-sample $\mathrm{t}$-tests $(\mathrm{df}=19)$, each of these percentages significantly exceeded the chance expectancy of 50\%. However, the ascorbic acid effect on the discrimination index was significant $\left(F_{(3,72)}=5.68\right.$, $\mathrm{p}<0.002$ ) because of the index being significantly higher for the $160 \mathrm{mg} / \mathrm{kg} /$ day group than for any other group (outlined in Figure 3). As shown in Table 1, females and males did not differ significantly on either total contacts with both objects or the discrimination index.

Table 1. Comparison of results in the open field, elevated plus maze, and novel object recognition test for female and male rats.

\begin{tabular}{lllll}
\hline Response & Females & Males & $\mathbf{F}_{(1,72)}$ & $\mathbf{P}$ \\
\hline Open field: & & & & \\
\hline Emergence latencies & $56.60(6.68)$ & $136.96(25.36)$ & 8.04 & $<0.006$ \\
Ambulation & $58.94(6.69)$ & $41.50(1.18)$ & 66.13 & $<0.0001$ \\
Walking & $61.52(1.14)$ & $62.92(1.17)$ & 2.11 & $>0.1$ \\
Rearing & $31.26(1.17)$ & $28.26(1.04)$ & 3.67 & 0.058 \\
Grooming & $8.12(1.52)$ & $7.90(0.84)$ & 0.45 & $>0.5$ \\
Center occupancy & $4.44(0.42)$ & $1.64(0.23)$ & 35.94 & $<0.0001$ \\
Corner occupancy & $50.48(1.20)$ & $60.38(1.21)$ & 34.20 & $<0.0001$ \\
\hline Elevated plus maze: & & & & \\
\hline \% open-arm observations & $46.84(1.86)$ & $39.37(1.88)$ & 10.86 & $<0.002$ \\
\% open-arm entries & $47.79(1.04)$ & $46.13(1.33)$ & 1.98 & $>0.1$ \\
Total closed-arm entries & $10.48(0.33)$ & $8.82(0.37)$ & 11.65 & $<0.002$ \\
\hline Novel object recognition: & & & & \\
\hline Total object contacts & $20.55(2.10)$ & $16.60(1.53)$ & 2.32 & $>0.5$ \\
Discrimination index & $0.33(0.04)$ & $0.36(0.05)$ & 0.01 & $>0.9$ \\
\hline
\end{tabular}

Mean \pm SEM values for all responses recorded in the open field and elevated plus maze, and novel object recognition test for female and male rats exposed to water or 61,114 or $160 \mathrm{mg} / \mathrm{kg}$ /day of ascorbic acid (exposure conditions combined), plus results of ANOVAs for sex differences. 


\section{Discussion}

Although the approximate target dose of $60 \mathrm{mg} / \mathrm{kg}$ of ascorbic acid was nearly achieved for the lowest dose (i.e., $61 \mathrm{mg} / \mathrm{kg} /$ day), the doses fell short of the goals by $5 \%$ for the $120 \mathrm{mg} / \mathrm{kg}$ (i.e., 114 $\mathrm{mg} / \mathrm{kg} /$ day) and $11 \%$ for the $180 \mathrm{mg} / \mathrm{kg} /$ day (i.e., $160 \mathrm{mg} / \mathrm{kg} /$ day) targets. However, these short-falls were trivial and still resulted in levels of ascorbic acid that were sufficient for possible doseresponse relationships to be examined. They were equivalent to $0.59,1.11$ and $1.56 \mathrm{~g} /$ day, respectively for a human which are well within the safe range $[\mathbf{2 3}, \mathbf{2 4}]$. Although there was no statistically significant main effect of the treatment in the daily volumes of fluid drunk, the greater relative volume consumed by females than by male rats was consistent with previous findings $[\mathbf{9}, \mathbf{3 4}]$ and was no doubt due to the females' higher level of diuresis arising from their lower levels of antidiuretic hormones $[35,36]$.

Even though there was evidence of anxiolytic effects of ascorbic acid on behavior in the OF, the doses that were effective in this respect depended on the particular response recorded. For example, frequencies of walking within or between squares (but not ambulation or distance traveled) were increased by both higher doses, whereas rearing was increased only by the lowest dose. It was also notable that, irrespective of dose, all ascorbic acid-treated rats combined were seen to be significantly less immobile than control subjects. However, observations in the open arms of the EPM were increased only by the lowest dose. While all these results were indicative of reduced anxiety $[10,11,29]$, they clearly did not reflect a linear dose-response relationship. Although center and corner occupancy in the OF were previously increased and decreased respectively by $80 \mathrm{mg} / \mathrm{kg} /$ day of ascorbic acid, thereby suggesting anxiolysis [9], neither response was affected in the present study apart from a significantly higher frequency of the former response with $160 \mathrm{mg} / \mathrm{kg} /$ day compared with $114 \mathrm{mg} / \mathrm{kg} /$ day (consistent with greater anxiolysis). Inspection of the results outlined for OF rearing and especially open-arm observations in the EPM suggest that, overall, $61 \mathrm{mg} / \mathrm{kg} /$ day of ascorbic acid probably exerted the greatest anxiolytic effect on the rats.

The shorter emergence latencies and higher frequencies of rearing and center occupancy, plus lower frequencies of corner occupancy in the OF shown by female than by male rats are consistent with the view that they are the less anxious or emotionally reactive of the two sexes [37]. The same conclusion would apply to females' higher frequencies of open-arm observations in the EPM. However, the higher frequencies of female OF ambulation and EPM closed-arm entries were probably more likely to have been due to their higher activity level [38].

The significantly highest NOR discrimination index with $160 \mathrm{mg} / \mathrm{kg} /$ day of ascorbic acid suggests that this dose had improved the rats' recognition memory. This outcome is in line with the finding that $125 \mathrm{mg} / \mathrm{kg}$ of acute intravenous ascorbic acid improved spatial memory in mice [19], and that $120 \mathrm{mg} /$ $\mathrm{kg}$ of chronic oral ascorbic acid enhanced retention of a passive avoidance task [18]. To our knowledge, ascorbic acid-related enhanced recognition memory has not been previously reported.
On balance, most of the results obtained in the OF and especially the EPM (which is generally regarded as preferable for measuring rodent anxiety, [39]) were consistent with anxiolytic effects of ascorbic acid reported by a number of previous authors (described in the Introduction). These effects appeared to be most typical of $61 \mathrm{mg} / \mathrm{kg} / \mathrm{day}$, which is approximately within the range shown previously to be anxiolytic [9]. It is therefore possible that doses considerably in excess of $60-80 \mathrm{mg} / \mathrm{kg} /$ day (i.e., 0.73-0.98 g/day for an average human) may not reliably exert anxiety-reducing effects. However, a different conclusion seems appropriate for enhancement of recognition memory as this only occurred with a dose of $180 \mathrm{mg} / \mathrm{kg} /$ day. Although such a chronic intake that typified the present study is clearly not therapeutically realistic as treatment for human anxiety or memory disorders, the common practice for many people to consume vitamin $\mathrm{C}$ daily for other health-related reasons might also help protect anxiety-prone individuals from deleterious psychological effects of stress and/or provide some protection from disease- or age-related memory impairment.

While the mechanism for ascorbic acid's anxiolytic action remains to be conclusively established, possibilities include NMDA antagonism [40], ascorbate-related reduction of brain oxidative stress (that has been implicated in anxiety, [41]) and serotonin regulation [42]. Alternatively, ascorbic acid-induced anxiolysis might merely be due to attenuation of the stress hormone, cortisol $[3,5]$. Although ascorbic acid's memory-enhancing effects have also been related to its antioxidant properties [43], there is evidence that it functions as a modulator of brain neurotransmitters that are important for memory, such as acetylcholine, dopamine, glutamate and GABA [2]. Since, contrary to its anxiolytic action, ascorbic acid improved recognition of a novel object only with the highest dose, it is likely that different central mechanisms are involved in the vitamin's effects on anxiety and memory. Clearly, further research is required to firmly establish critical doses for anxiolytic and memory-enhancing effects of ascorbic acid, as well as the central mechanisms responsible.

\section{Conclusions}

The effects of chronic ascorbic acid treatment on OF walking, rearing and immobility, and occupation of the EPM open arms in rats confirmed the anxiolytic nature of the substance suggested in previous research. In this respect, the lowest dose of $61 \mathrm{mg} / \mathrm{kg} /$ day appeared to be the most effective. However, only the highest dose of $160 \mathrm{mg} / \mathrm{kg} /$ day improved recognition memory as measured by the NOR test. From observations of their anxiety-related behavior and consistent with previous findings, female rats were less anxious (or emotionally reactive) than males. Overall, it was clear from the results of the present study that more research is required to establish critical doses for both the anxiolytic and memory-enhancing effects of ascorbic acid, and determine associated central mechanisms.

\section{Competing interests}

The authors declare that they have no competing interests. 


\section{Authors' contributions}

The study was designed by RNH who also analyzed all resulting data and drafted the manuscript. NJH treated the rats with ascorbic acid and conducted all behavioral testing and data collation. RMT was responsible for determining the lack of a significant preference for either object used in the NOR test.

\section{Acknowledgement}

This study was supported by an internal research grant from the Department of Psychology, University of Canterbury.

\section{Publication history}

Editor: Vinay Parikh, Temple University, USA.

Received: 26 December 2014 Revised: 13 February 2015

Accepted: 02 March 2015 Published: 04 March 2015

\section{References}

1. Fumeron C, Nguyen-Khoa T, Saltiel C, Kebede M, Buisson C, Drueke TB, Lacour $B$ and Massy ZA. Effects of oral vitamin C supplementation on oxidative stress and inflammation status in haemodialysis patients. Nephrol Dial Transplant. 2005; 20:1874-9. | Article | PubMed

2. Harrison FE and May JM. Vitamin C function in the brain: vital role of the ascorbate transporter SVCT2. Free Radic Biol Med. 2009; 46:719-30. | Article | PubMed Abstract | PubMed FullText

3. Brody S, Preut R, Schommer K and Schurmeyer TH. A randomized controlled trial of high dose ascorbic acid for reduction of blood pressure, cortisol, and subjective responses to psychological stress. Psychopharmacology (Berl). 2002; 159:319-24. | Article | PubMed

4. Jones RB, Satterlee DG, Moreau and Waddington D. Vitamin C supplementation and fear-reduction in Japanese quail: short-term cumulative effects. Br Poult Sci. 1996; 37:33-42. | Article | PubMed

5. Satterlee DG, Jones RB and Ryder FH. Effects of ascorbyl-2polyphosphate on adrenocortical activation and fear-related behavior in broiler chickens. Poult Sci. 1994; 73:194-201. | Article | PubMed

6. de Angelis $L$ and Furlan $C$. The effects of ascorbic acid and oxiracetam on scopolamine-induced amnesia in a habituation test in aged mice. Neurobiol Learn Mem. 1995; 64:119-24. | Article I PubMed

7. Choi J.Y, Choi Y.J, dela Peña I.K, Yoon S.Y, Lee G.S and Shin C.Y et al. Vitamin C supplementation alleviates electroshock stress but not restraint stress in ICR mice. Food SciBiotechnol. 2010; 19:137-44.

8. Angrini MA and Leslie JC. Vitamin C attenuates the physiological and behavioural changes induced by long-term exposure to noise. Behav Pharmacol. 2012; 23:119-25. | Article | PubMed

9. Hughes RN, Lowther $\mathrm{CL}$ and van Nobelen M. Prolonged treatment with vitamins $C$ and $E$ separately and together decreases anxiety-related open-field behavior and acoustic startle in hooded rats. Pharmacol Biochem Behav. 2011; 97:494-9. | Article | PubMed

10. Pellow S, Chopin P, File SE and Briley M. Validation of open:closed arm entries in an elevated plus-maze as a measure of anxiety in the rat. $J$ Neurosci Methods. 1985; 14:149-67. | Article I PubMed

11. Prut $L$ and Belzung $C$. The open field as a paradigm to measure the effects of drugs on anxiety-like behaviors: a review. Eur J Pharmacol. 2003; 463:3-33. | Article | PubMed

12. Pettenuzzo LF, Schuck PF, Fontella F, Wannmacher CM, Wyse AT, DutraFilho CS, Netto CA and Wajner M. Ascorbic acid prevents cognitive deficits caused by chronic administration of propionic acid to rats in the water maze. Pharmacol Biochem Behav. 2002; 73:623-9. | Article | PubMed

13. Harrison FE, Hosseini AH, Dawes SM, Weaver S and May JM. Ascorbic acid attenuates scopolamine-induced spatial learning deficits in the water maze. Behav Brain Res. 2009; 205:550-8. | Article | PubMed Abstract | PubMed FullText

14. Harrison FE, Hosseini AH, McDonald MP and May JM. Vitamin C reduces spatial learning deficits in middle-aged and very old APP/ PSEN1 transgenic and wild-type mice. Pharmacol Biochem Behav. 2009;
93:443-50. | Article | PubMed Abstract | PubMed FullText

15. Paleologos M, Cumming RG and Lazarus R. Cohort study of vitamin C intake and cognitive impairment. Am J Epidemiol. 1998; 148:45-50. | PubMed

16. Charlton KE, Rabinowitz TL, Geffen LN and Dhansay MA. Lowered plasma vitamin C, but not vitamin $\mathrm{E}$, concentrations in dementia patients. $J$ Nutr Health Aging. 2004; 8:99-107. | PubMed

17. Riviere S, Birlouez-Aragon I, Nourhashemi F and Vellas B. Low plasma vitamin C in Alzheimer patients despite an adequate diet. Int J Geriatr Psychiatry. 1998; 13:749-54. | PubMed

18. Shahidi S, Komaki A, Mahmoodi M, Atrvash N and Ghodrati M. Ascorbic acid supplementation could affect passive avoidance learning and memory in rat. Brain Res Bull. 2008; 76:109-13. | Article | PubMed

19. Kennard JA and Harrison FE. Intravenous ascorbate improves spatial memory in middle-aged APP/PSEN1 and wild type mice. Behav Brain Res. 2014; 264:34-42. | Article | PubMed Abstract | PubMed FullText

20. Bevins RA and Besheer J. Object recognition in rats and mice: a one-trial non-matching-to-sample learning task to study 'recognition memory'. Nat Protoc. 2006; 1:1306-11. | Article | PubMed

21. Reagan-Shaw $S$, Nihal $M$ and Ahmad N. Dose translation from animal to human studies revisited. FASEB J. 2008; 22:659-61. | Article I PubMed

22. Walpole SC, Prieto-Merino D, Edwards P, Cleland J, Stevens $G$ and Roberts I. The weight of nations: an estimation of adult human biomass. $B M C$ Public Health. 2012; 12:439. | Article | PubMed Abstract | PubMed FullText

23. Hathcock JN, Azzi A, Blumberg J, Bray T, Dickinson A, Frei B, Jialal I, Johnston CS, Kelly FJ, Kraemer K, Packer L, Parthasarathy S, Sies H and Traber MG. Vitamins $E$ and $C$ are safe across a broad range of intakes. Am J Clin Nutr. 2005; 81:736-45. | Article | PubMed

24. Johnston CS. Biomarkers for establishing a tolerable upper intake level for vitamin C. Nutr Rev. 1999; 57:71-7. I PubMed

25. Martinez JC, Cardenas F, Lamprea M and Morato S. The role of vision and proprioception in the aversion of rats to the open arms of an elevated plus-maze. Behav Processes. 2002; 60:15-26. | Article | PubMed

26. Hughes RN, Hancock NJ, Henwood GA and Rapley SA. Evidence for anxiolytic effects of acute caffeine on anxiety-related behavior in male and female rats tested with and without bright light. Behav Brain Res. 2014; 271:7-15. | Article | PubMed

27. Powell J, Martindale B, Kulp S, Martindale A and Bauman R. Taking a closer look: time sampling and measurement error. J Appl Behav Anal. 1977; 10:325-32. | Article | PubMed Abstract | PubMed FullText

28. Detke MJ, Rickels M and Lucki I. Active behaviors in the rat forced swimming test differentially produced by serotonergic and noradrenergic antidepressants. Psychopharmacology (Berl). 1995; 121:66-72. | PubMed

29. Archer J. Tests for emotionality in rats and mice: a review. Anim Behav. 1973; 21:205-35. | PubMed

30. Hughes RN. Adult anxiety-related behavior of rats following consumption during late adolescence of alcohol alone and in combination with caffeine. Alcohol. 2011; 45:365-72. | Article | PubMed

31. Hughes RN and Otto MT. Anxiolytic effects of environmental enrichment attenuate sex-related anxiogenic effects of scopolamine in rats. Prog Neuropsychopharmacol Biol Psychiatry. 2013; 40:252-9. | Article | PubMed

32. Cruz AP, Frei F and Graeff FG. Ethopharmacological analysis of rat behavior on the elevated plus-maze. Pharmacol Biochem Behav. 1994; 49:171-6. | Article | PubMed

33. Sutcliffe JS, Marshall KM and Neill JC. Influence of gender on working and spatial memory in the novel object recognition task in the rat. Behav Brain Res. 2007; 177:117-25. | Article | PubMed

34. Hughes RN and Collins MA. Enhanced habituation and decreased anxiety by environmental enrichment and possible attenuation of these effects by chronic alpha-tocopherol (vitamin E) in aging male and female rats. Pharmacol Biochem Behav. 2010; 94:534-42. | Article | PubMed 
Hughes et al. Journal of Psychiatry and Brain Functions 2015, http://www.hoajonline.com/journals/pdf/2055-3447-2-4.pdf

35. McGivern RF, Henschel D, Hutcheson M and Pangburn T. Sex difference in daily water consumption of rats: effect of housing and hormones. Physiol Behav. 1996; 59:653-8. I Article I PubMed

36. Wang YX, Edwards RM, Nambi P, Stack EJ, Pullen M, Share L, Crofton JT and Brooks DP. Sex difference in the antidiuretic activity of vasopressin in the rat. Am J Physiol. 1993; 265:R1284-90. | Article | PubMed

37. Gray JA. Sex differences in emotional behaviour in mammals including man: endocrine bases. Acta Psychol (Amst). 1971; 35:29-46. | Article | PubMed

38. Archer J. Rodent sex differences in emotional and related behavior. Behav Biol. 1975; 14:451-79. | PubMed

39. Bourin M, Petit-Demouliere B, Dhonnchadha BN and Hascoet M. Animal models of anxiety in mice. Fundam Clin Pharmacol. 2007; 21:567-74. | Article I PubMed

40. Majewska MD, Bell JA and London ED. Regulation of the NMDA receptor by redox phenomena: inhibitory role of ascorbate. Brain Res. 1990; 537:328-32. | Article | PubMed

41. Bouayed J, Rammal H and Soulimani R. Oxidative stress and anxiety: relationship and cellular pathways. Oxid Med Cell Longev. 2009; 2:63-7. | PubMed Abstract | PubMed FullText

42. Lee L, Kang SA, Lee HO, Lee BH, Jung IK, Lee JE and Hoe YS. Effect of supplementation of vitamin $E$ and vitamin $C$ on brain acetylcholinesterase activity and neurotransmitter levels in rats treated with scopolamine, an inducer of dementia. J Nutr Sci Vitaminol (Tokyo). 2001; 47:323-8. I PubMed

43. Castagne V, Rougemont M, Cuenod M and Do KQ. Low brain glutathione and ascorbic acid associated with dopamine uptake inhibition during rat's development induce long-term cognitive deficit: relevance to schizophrenia. Neurobiol Dis. 2004; 15:93-105. | Article I PubMed

\section{Citation:}

Hughes N.R, Hancock J.N and Thompson R.M. Anxiolysis and recognition memory enhancement with long-term supplemental ascorbic acid (vitamin $\mathrm{C}$ ) in normal rats: possible dose dependency and sex differences.

J Psychiatry Brain Funct. 2015; 2:4.

http://dx.doi.org/10.7243/2055-3447-2-4 